\title{
Using High-Speed Photography to Study Undercatch in Tipping-Bucket Rain Gauges*
}

\author{
Claude Duchon \\ School of Meteorology, University of Oklahoma, Norman, Oklahoma \\ CHRISTOPHER FIEBRICH AND DAVID GRIMSLEY \\ Oklahoma Climatological Survey, Norman, Oklahoma
}

(Manuscript received 15 August 2013, in final form 5 December 2013)

\begin{abstract}
To better understand the undercatch process associated with tipping-bucket rain gauges, a high-speed camera normally used in determining the structure of lightning was employed. The photo rate was set at 500 frames per second to observe the tipping of the bucket in a commonly used tipping-bucket rain gauge. The photos showed detail never seen before as the bucket tipped from one side to the other. Two fixed rain rates of $19.9 \mathrm{~mm} \mathrm{~h}^{-1}\left(0.78 \mathrm{in} . \mathrm{h}^{-1}\right)$ and $175.2 \mathrm{~mm} \mathrm{~h}^{-1}\left(6.90 \mathrm{in} \cdot \mathrm{h}^{-1}\right)$, the minimum and maximum available, respectively, were used.

The data from four tips at each rain rate were examined. The results show that the time from the beginning of a tip to the time the bucket assembly is horizontal—defined as the period during which undercatch occurs-was an average of $0.450 \mathrm{~s}$ for the eight cases. The average time for a complete tip was $0.524 \mathrm{~s}$; thus, the vast majority of the time of a tip, $86 \%$, is spent in undercatch mode. Because there was no apparent dependence of these times on rain rate, it should be possible to apply an accurate linear correction for undercatch as a function of rain rate given the time that undercatch occurs during a tip. Over all eight tips, the undercatch was found to be $0.98 \%$ for the $19.9 \mathrm{~mm} \mathrm{~h}^{-1}$ rate and $8.78 \%$ for the $175.2 \mathrm{~mm} \mathrm{~h}^{-1}$ rate. The procedure used to estimate the undercatch is described. Slow motion videos of the tipping of a bucket are available online.
\end{abstract}

\section{Introduction}

Undercatch of rain measured by tipping-bucket gauges as rain rate increases is well known (Parsons 1941; WMO 2008; Humphrey et al. 1997; Duchon and Essenberg 2001; Sieck et al. 2007; Habib et al. 2008, Duchon and Biddle 2010). When a high-speed camera and associated analysis software became temporarily available to us, we decided to take advantage of the opportunity to examine, in detail, the life cycle of a bucket

\footnotetext{
* Supplemental information related to this paper is available at the Journals Online website: http://dx.doi.org/10.1175/JTECH-D13-00169.s1.

Corresponding author address: Claude E. Duchon, School of Meteorology, University of Oklahoma, 120 David L. Boren Blvd., Norman, OK 73072.

E-mail: cduchon@ou.edu
}

tip. The camera we used was a Photron FASTCAM SA1.1. ${ }^{1}$ This is a type of camera used to investigate the structure of lightning strokes (Petersen and Beasley 2013; Hill et al. 2011). For our needs, we set the frame rate at a comparatively low rate of 500 frames per second (fps), yielding a resolution of $0.002 \mathrm{~s}$. The rain gauge we used was a Met One model 380 12-in. diameter collector, ${ }^{2}$ an example of which is shown in its natural setting in Fig. 1. This model is used throughout the 120-station Oklahoma Mesonet (Brock et al. 1995; McPherson et al. 2007). The tipping bucket itself is shown in Fig. 2.

Other sources of error that would be encountered in field measurements of precipitation, such as the wetting of the collector at the initiation of precipitation, subsequent evaporation, and undercatch caused by

\footnotetext{
${ }^{1}$ Photron USA, San Diego, California.

${ }^{2}$ Met One Instruments, Grants Pass, Oregon.
} 


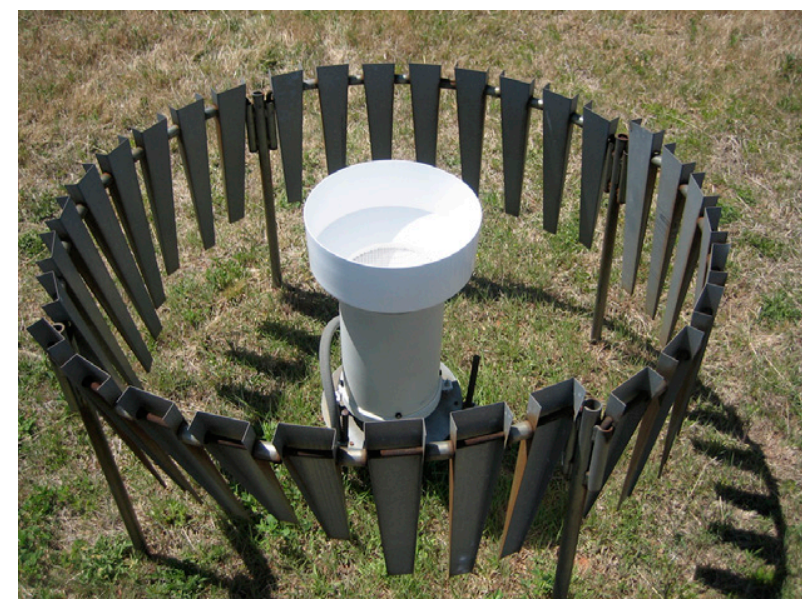

FIG. 1. A Met One model 380 (12-in. diameter, 0.01 in. per tip) tipping-bucket rain gauge with an Alter windshield.

wind, are not addressed here. Our primary interest is in laboratory measurements of undercatch using highspeed photography.

\section{Laboratory setup}

Figure 3 shows a Met One gauge mounted over a sink with the Photron camera and light source in the foreground. The gauge housing was cut so that the tipping-bucket assembly would be visible. The water dispenser was a model TB 320 field calibration device, ${ }^{3}$ the elements of which are shown in Fig. 4. After the dispenser was filled with water and one of the five nozzles attached, the dispenser was inverted and placed in the tripod in the collector. The diameters of the nozzle openings were such that rain rates for the 12-in.-diameter collector were 19.9, 43.6, 85.3, 107.1, and $175.2 \mathrm{~mm} \mathrm{~h}^{-1}$ (equivalently, 0.78, $1.72,3.36,4.22$, and $6.90 \mathrm{in}^{-\mathrm{h}^{-1}}$ ). A plug in the air tube was removed to initiate the release of the stream of water from the dispenser onto the side of the collector. The arrangement is shown in Fig. 5.

\section{High-speed photography}

We recorded a total of eight tips, four at the lowest rain rate $\left(19.9 \mathrm{~mm} \mathrm{~h}^{-1}\right)$ and four at the highest rate $\left(175.2 \mathrm{~mm} \mathrm{~h}^{-1}\right)$. We chose these two rain rates because they were the extremes available to us. Although the $175.2 \mathrm{~mm} \mathrm{~h}^{-1}$ rate seldom occurs locally, we needed to know whether high-speed photography was a viable method to observe and estimate undercatch over a wide range of rain rates.

\footnotetext{
${ }^{3}$ Hydrologic Services, Sydney, New South Wales, Australia.
}

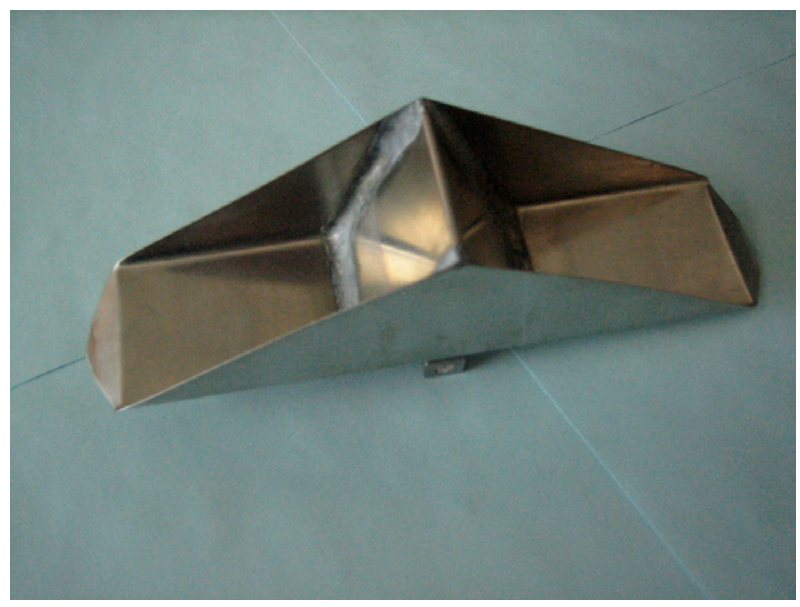

FIG. 2. The tipping bucket used in the Met One 380 gauge. Its length from lip tip to lip tip is $17.2 \mathrm{~cm}$.

The recorded tips were taken at times of opportunity during the release of water from the dispenser and after the first tip (to ensure the interior surfaces of the bucket were similarly wetted). In addition, no back-to-back tips were recorded among the 30-37 tips required to empty the dispenser depending on which nozzle was used. In short, the four tips in each set of tips are independent of each other.

Figure 6 is a photo of the bucket at rest. We know the bucket is at rest because the reflection of the nylon stop post just touches the nylon post itself. The bucket is designed to tip every $0.254 \mathrm{~mm}$ ( $0.01 \mathrm{in}$.) with fine-tuning accomplished by individually adjusting the height of each stop post. As noted earlier, the duration of each photo is $0.002 \mathrm{~s}$ (less $1 \mu \mathrm{s}$ for its transmission). To display

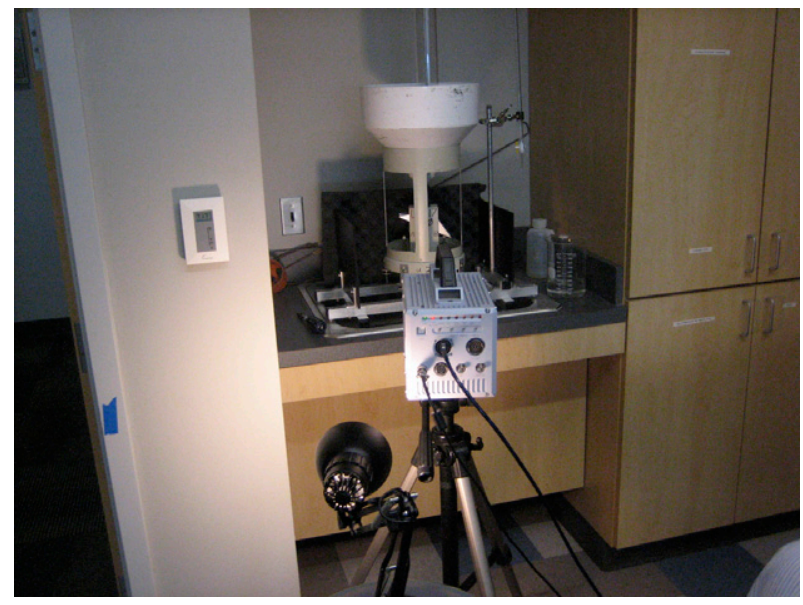

FIG. 3. The laboratory setup for photographing the bucket as it tips. The high-speed camera and light source are in the foreground, and a cutaway of the rain gauge and the water dispenser are in the background. 


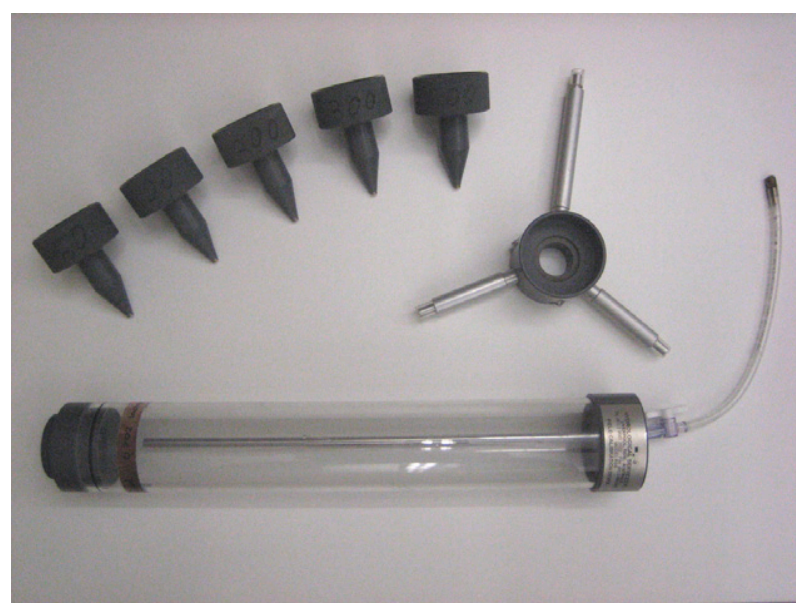

FIG. 4. Components of the field calibration device: water dispensing tube, nozzles to control flow rate, and the offset tripod that holds the dispenser.

a complete tip with comparatively few photos, we selected every 30th photo. Figure 7 shows 10 successive cropped photos of the positions of the bucket during a tip as it rotated clockwise starting when the bucket was just leaving the left post to when it struck the right post for the first time $0.54 \mathrm{~s}$ later. The first strike could be determined within $0.002 \mathrm{~s}$ using the original set of photos.

There are two points to be made from Fig. 7. The first is to emphasize that the rate of rotation is very nonlinear. When the bucket just begins to leave its stop post, the instant of which, in fact, is somewhat subjective, the rotation rate is very slow. The bottom-left panel indicates it takes approximately $0.48 \mathrm{~s}$ for the bucket to become horizontal and just about $0.06 \mathrm{~s}$ more to complete the tip. The bucket reaches its maximum rotation rate just as it strikes the opposite post. The second point is that undercatch occurs from the moment the bucket leaves the stop post until it is horizontal. Ideally, when the bucket accumulates the volume equivalent of $0.254 \mathrm{~mm}$ of rain, it immediately begins rotation, instantly strikes the opposite stop post, and filling of the empty side of the bucket commences. In reality, rotation takes time and filling of the empty side only begins when the rotating bucket becomes horizontal. Rain falling during the time it takes for the bucket to become horizontal is unaccounted for-this is the undercatch. It is clear from the sequence of figures that the period of undercatch accounts for a large majority of the time of a tip.

Videos of the tipping of a bucket can be seen in the supplemental material.

One video is for a rain rate of $175.2 \mathrm{~mm} \mathrm{~h}^{-1}\left(6.90 \mathrm{in.} \mathrm{h}^{-1}\right)$ and the other is for a rain rate of $19.9 \mathrm{~mm} \mathrm{~h}^{-1}\left(0.78 \mathrm{in.} \mathrm{h}^{-1}\right)$. The videos were taken at $500 \mathrm{fps}$ and slowed by a factor

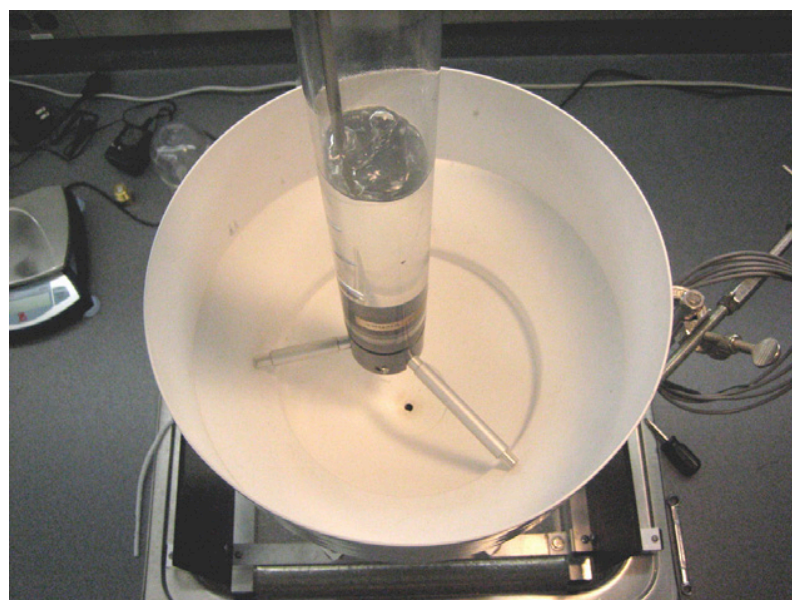

FIG. 5. The components in Fig. 4 assembled in the collector of the rain gauge.

of 20. Multiple bounces of the bucket on the stop post can be easily seen in both videos.

\section{Analysis and results}

To measure the time required for a tip, the period of undercatch, and the increasing rate of rotation of the bucket after it leaves the stop post, an image of a protractor was overlaid onto every tenth photo (0.02-s separation) beginning with the one showing the first strike and counting backward in time until prior to the

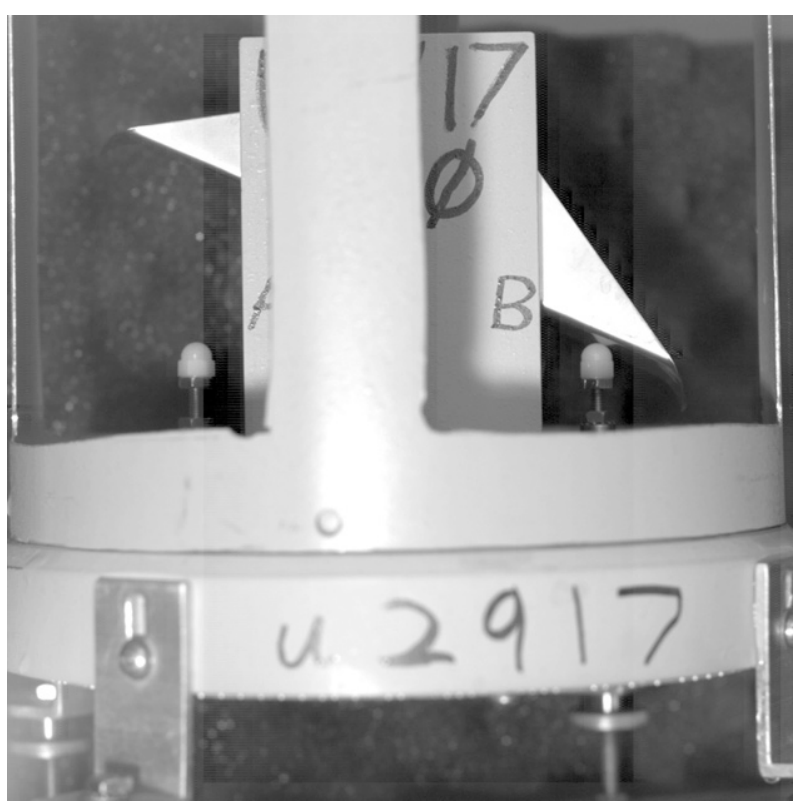

FIG. 6. A typical photo taken every $0.002 \mathrm{~s}$. In this example, the bucket is resting on a nylon acorn stop post. 


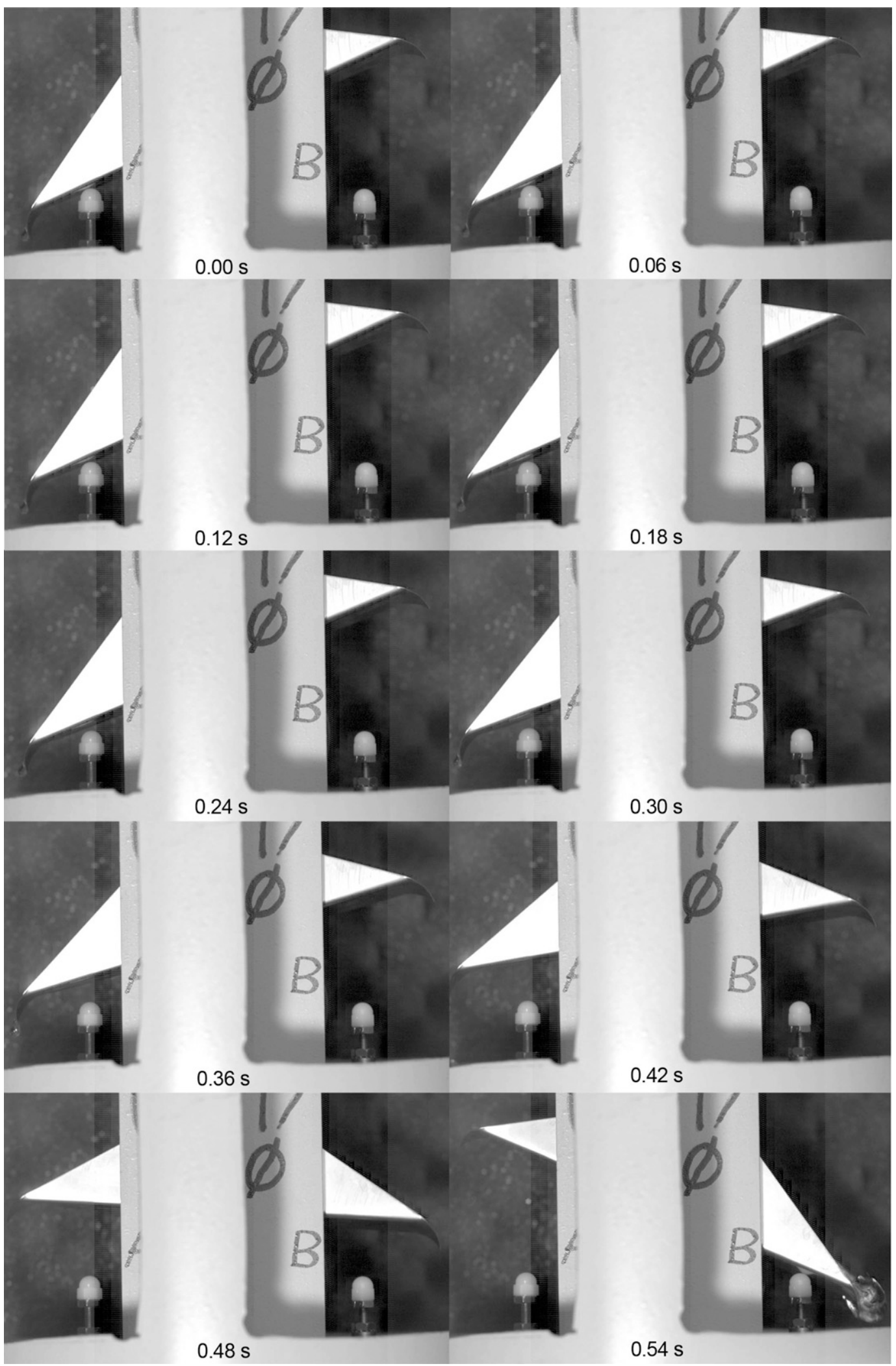

FIG. 7. A sequence of 10 cropped photos $0.06 \mathrm{~s}$ apart encompassing a complete tip. Videos of two tips taken at 500 fps slowed by a factor of 20 can be seen online (see the supplemental material ). See text for details. 


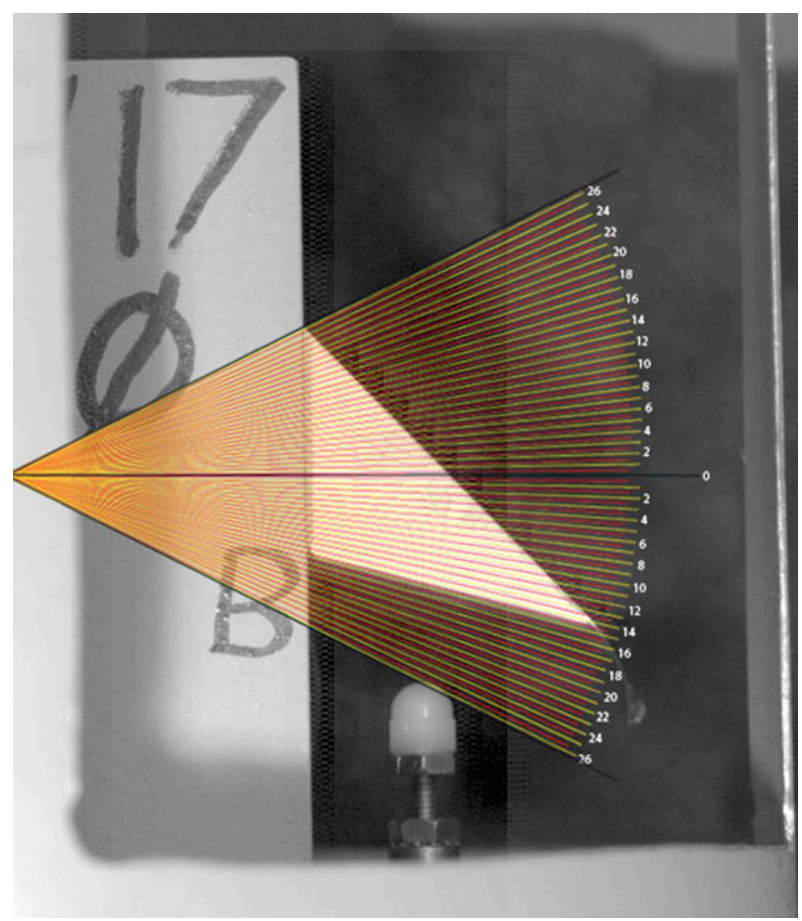

FIG. 8. A protractor scale overlaid on a photo image from which the bucket angle is estimated. Horizontal corresponds to $0^{\circ}$.

start of a tip. Figure 8 shows the protractor with $0^{\circ}$ horizontal angle and angular values increasing radially in either direction to $26^{\circ}$ (one direction was declared negative). By zooming in on the image and matching the base of the bucket to its location between the lines of the protractor, the angle of the bucket was estimated to $0.1^{\circ}$ resolution. The angle in Fig. 8 is $14.4^{\circ}$. A companion protractor image was created for the left side of the bucket (not shown).

Figure 2 shows that the axis of rotation of the bucket is below the base of the bucket; the distance is $6 \mathrm{~mm}$. In framing the protractor, we assumed the center of rotation to be the center of the line delineating the base of the bucket with the bucket in the horizontal position. In fact, the assumed center of rotation that we used moves approximately $5 \mathrm{~mm}$ during the course of tip. Within our ability to estimate the exact angle of the bucket, the effect of this displacement is inconsequential.

Figure 9 shows the angle of rotation as a function of time for each of the eight tips derived from the analysis described above using the protractor and photos. As stated earlier, the instant of first strike can be accurately determined; it was given the arbitrary time of $0.9 \mathrm{~s}$. Table 1 gives the details of each tip and the percent of time of tip that undercatch occurs. Over the eight tips the average time of tip was $0.524 \mathrm{~s}$ and the average time of

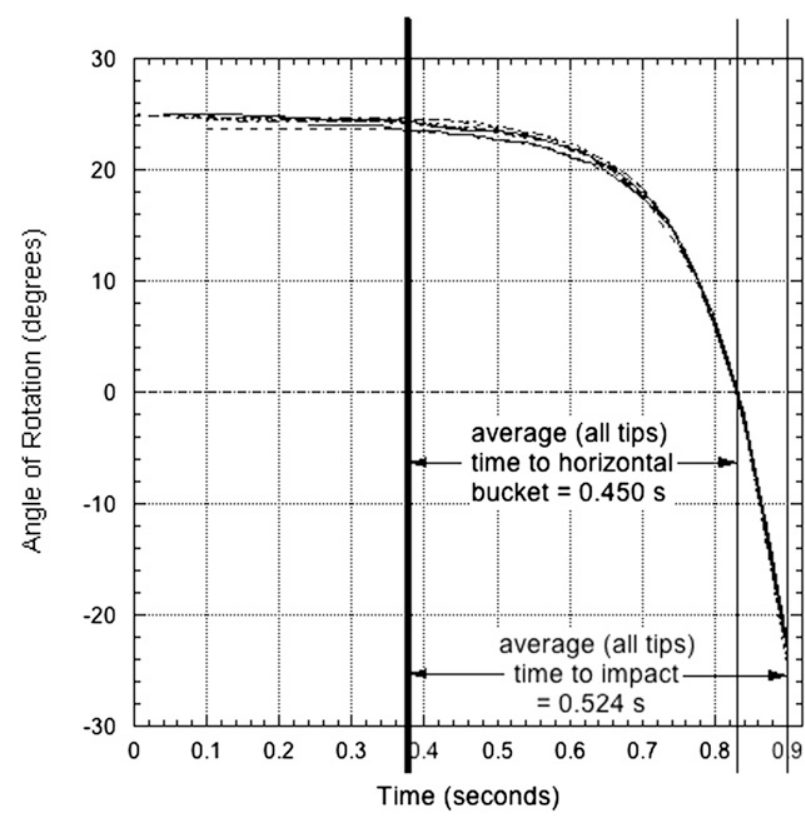

FIG. 9. The angle of rotation of the bucket for each of the eight tips as a function of time from start of tip to first strike. The bucket is horizontal at $0^{\circ}$.

undercatch was $0.450 \mathrm{~s}$, so that undercatch occurred during $86 \%$ of the time of tip.

The formula for calculating undercatch error associated with a tip is

$$
\text { undercatch } \operatorname{error}(\%)=\frac{R_{r} T}{A_{t}} \times 100 \%,
$$

where $R_{r}$ is the rain rate (converted to $\mathrm{mm} \mathrm{s}^{-1}$ ); $T$ is the time (s) from the start of a tip until the bucket is horizontal, or the time of undercatch; and $A_{t}$ is the accumulation per tip ( $0.254 \mathrm{~mm}$ for our test gauge). Table 2 shows the computed errors for the two rain rates and the average values of $T$ for the four tips associated with each rain rate and the average $T$ over all eight tips. The

TABLE 1. Details of each of the eight tips. $\mathrm{R}$ is right; $\mathrm{L}$ is left.

\begin{tabular}{cccccc}
\hline Tip & $\begin{array}{c}\text { Rain } \\
\text { rate } \\
\text { No. }\end{array}$ & $\begin{array}{c}\text { Direction } \\
\text { of tip }\end{array}$ & $\begin{array}{c}\text { Time: } \\
\text { start to } \\
0^{\circ}(\mathrm{s})\end{array}$ & $\begin{array}{c}\text { Time: start } \\
\text { to first } \\
\text { strike }(\mathrm{s})\end{array}$ & $\begin{array}{c}\text { Time in } \\
\text { undercatch } \\
(\%)\end{array}$ \\
\hline 1 & 19.9 & R to L & 0.48 & 0.56 & 86 \\
2 & 19.9 & L to R & 0.40 & 0.47 & 85 \\
3 & 19.9 & L to R & 0.44 & 0.51 & 86 \\
4 & 19.9 & R to L & 0.45 & 0.53 & 85 \\
5 & 175.2 & L to R & 0.46 & 0.53 & 87 \\
6 & 175.2 & L to R & 0.44 & 0.51 & 86 \\
7 & 175.2 & L to R & 0.46 & 0.53 & 87 \\
8 & 175.2 & R to L & 0.47 & 0.55 & 85 \\
& & Avg & 0.450 & 0.524 & 86 \\
\hline
\end{tabular}


TABLE 2. Undercatch error as a function of rain rate and the average time from the beginning of a tip to the time the bucket is horizontal for the four tips associated with each rain rate and over all eight tips.

\begin{tabular}{lcccc}
\hline \hline Rain rate $\left(R_{r}\right)$ & $19.9 \mathrm{~mm} \mathrm{~h}^{-1}\left(0.78 \mathrm{in} . \mathrm{h}^{-1}\right)$ & $175.2 \mathrm{~mm} \mathrm{~h}^{-1}\left(6.90 \mathrm{in} . \mathrm{h}^{-1}\right)$ \\
Avg time: start to $0^{\circ}(\mathrm{s})$ & $T_{1-4}=0.443$ & $T_{1-8}=0.450$ & $T_{5-8}=0.458$ & $T_{1-8}=0.450$ \\
Undercatch error $(\%)$ & -0.96 & -0.98 & -8.78 & -8.62 \\
\hline
\end{tabular}

undercatch for the lower rain rate is slightly less than $1 \%$ and for the higher rain rate it is more than $8 \%$. We observe that for the two available extreme rain rates, the average time of undercatch $T$ for the higher rate is $0.015 \mathrm{~s}$ greater than for the lower rain rate; or, stated otherwise, there is approximately a $3.3 \%$ difference between the time of undercatch between the two extreme rain rates. Given that the extreme $R_{r}$ differ by a factor of 8.8 or $880 \%$ and the starting time of a tip cannot be determined exactly, the conclusion is that the undercatch error is a linear function of rain rate, at least based on the above analysis of photographic data and assuming no other effects. If this is true, in general, then the only reason the undercatch error would change from one tipping-bucket rain gauge to another is the time of undercatch $T$.

\section{Comparison with traditional calibration}

It was mentioned in section 1 that the rain gauge used in this study is the same model as that used in the 120-station Oklahoma Mesonet. Each gauge is periodically calibrated in the laboratory by comparing the observed number of tips with the expected number of tips for each of the five nozzles in Fig. 4 given the known volume of water in the dispenser and the volume in the bucket for each $0.254-\mathrm{mm}$ (0.01 in.) tip. Each calibration for a given gauge yields a different calibration curve.

Figure 10 is a comparison of the undercatch error versus rain rate calculated using the high-speed camera method (i.e., from the data in Table 2) with the average of two traditional laboratory calibrations surrounding the date of the photo calibration (2 July 2010). The laboratory calibration data were fitted with a seconddegree polynomial and the photographic data with a firstdegree polynomial (perforce). As expected, the two photo calibration curves-one taking into account the average undercatch time associated with each rain rate, the other using the overall average undercatch timeare quite close. It is interesting that they both intersect $0 \%$ accumulation error at zero rain rate, while the laboratory calibration curve accumulation error is about $1.6 \%$ at zero rain rate.

What accounts for the separation between the laboratory calibration curve determined by the traditional method and the calibration curves determined from photography? We first need to realize that the equation for undercatch error given above only takes into account the time $T$ from the start of a tip until the bucket is horizontal. The equation correctly determines undercatch error due to the time of undercatch $T$, while a traditional calibration includes other effects as well. We can associate the term "total undercatch" with a traditional calibration. These "other effects" could include, for example, variable wetting of the interior walls of the bucket, perhaps influenced by irregularities in soldering (see Fig. 2), and turbulence in the accumulated water in the bucket generated by the stream of water entering the bucket. As Fig. 10 shows, the consequence of these additional effects is overcatch; that is, the traditional calibration curve is everywhere above the photographic calibration curves. Whether this relationship is true, in general, is unknown.

Humphrey et al. (1997, their Fig. 4), using tippingbucket gauges from a different manufacturer, also show nonlinear calibration behavior similar to the traditional

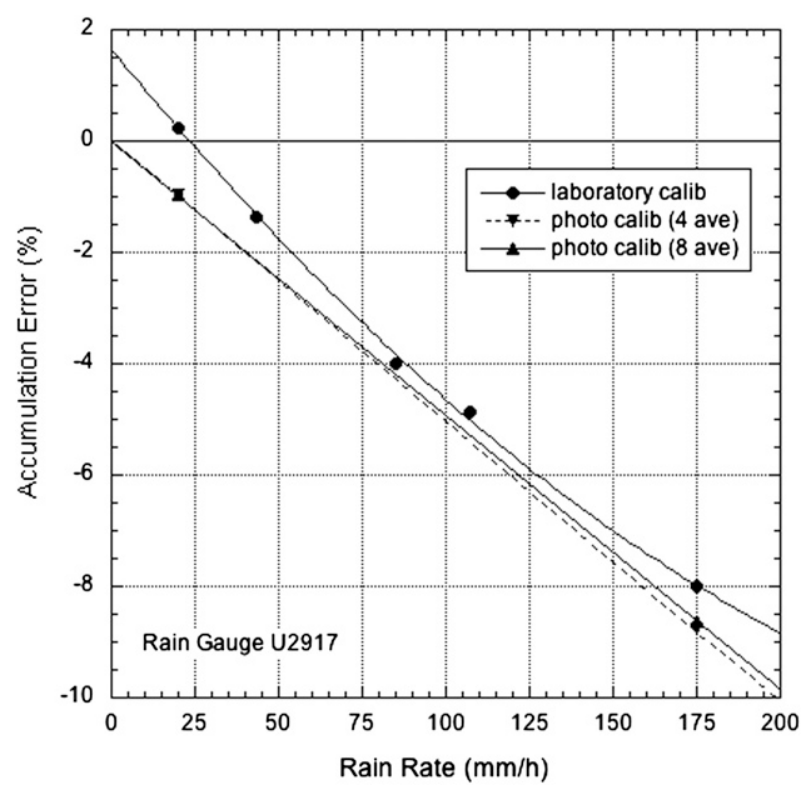

FIG. 10. Comparison of undercatch error with rain rate using photographic data for the two rain rates given in Table 2 and the average of two traditional laboratory calibrations before and after the photo observations. 
calibration in Fig. 10. However, the magnitude of their undercatch is much larger for rain rates away from zero rain rate.

\section{Summary and conclusions}

Historically, dynamic laboratory calibrations have shown that tipping-bucket gauges experience increasing undercatch error as rain rate increases. We view a dynamic calibration to have two components: one is entirely due to undercatch that occurs from the beginning of a tip until the bucket is horizontal; the other comprises all remaining effects present in a calibration. The total undercatch is the sum of the two components. This study indicates that the latter component is small relative to the former. Therefore, it should be possible to approximately correct for total undercatch with only knowledge of the time of undercatch $T$ and observed rain rate. Using $T$ alone to determine total undercatch will likely result in its overestimation, based on the example in Fig. 10. We expect $T$ will have a slightly different value for each tipping-bucket gauge, but verification remains.

To our knowledge, the high-speed photography experiment described in this paper is the first time the phenomenon that causes undercatch has been carefully documented. The use of high-speed photography has the potential to become a practical method for assessing undercatch in tipping-bucket rain gauges. There are, however, a number of issues to consider for this to happen, including the following:

1) A relatively high-speed camera is needed. A frame rate of $500 \mathrm{fps}$ (period of $0.002 \mathrm{~s}$ ) is adequate. Moderately priced digital cameras with this frame rate are available.

2) A laboratory setup with good lighting is required, so that the edge of the bucket can be optically identified as a function of angle.

3) The laboratory procedure needs to be automated, in particular, determining the angle of the bucket as a function of time. The manual method we used (inspecting hundreds of photos, one at a time) was a time-consuming effort.
Acknowledgments. Many thanks to Ryan Brashear for carrying out the traditional laboratory calibrations. William Beasley was kind enough to lend us his Photron high-speed camera. Danyal Petersen patiently explained to us how to use the software package to create the numerous image files. Lacie Webb developed the protractor images for determining the angle of rotation of the bucket.

\section{REFERENCES}

Brock, F. V., K. C. Crawford, R. L. Elliott, G. W. Cuperus, S. J. Stadler, H. L. Johnson, and M. D. Eilts, 1995: The Oklahoma Mesonet: A technical review. J. Atmos. Oceanic Technol., 12, 5-19, doi:10.1175/1520-0426(1995)012<0005:TOMATO >2.0.CO;2.

Duchon, C. E., and G. R. Essenberg, 2001: Comparative rainfall observations from pit and aboveground rain gauges with and without wind shields. Water Resour. Res., 37, 3253-3263, doi:10.1029/2001WR000541.

_ , and C. J. Biddle, 2010: Undercatch of tipping-bucket gauges in high rain rate events. $A d v$. Geosci., 25, 11-15, doi:10.5194/ adgeo-25-11-2010.

Habib, E. H., E. A. Meselhe, and A. V. Aduvala, 2008: Effect of local errors of tipping-bucket rain gauges on rainfall-runoff simulations. J. Hydrol. Eng., 13, 488-496, doi:10.1061/ (ASCE)1084-0699(2008)13:6(488).

Hill, J. D., M. A. Uman, and D. M. Jordan, 2011: High-speed video observations of a lightning stepped leader. J. Geophys. Res., 116, D16117, doi:10.1029/2011JD015818.

Humphrey, M. D., J. D. Istok, J. Y. Lee, J. A. Hevesi, and A. L. Flint, 1997: A new method for automated dynamic calibration of tipping-bucket rain gauges. J. Atmos. Oceanic Technol., 14, 1513-1519, doi:10.1175/1520-0426(1997)014<1513: ANMFAD $>2.0 . \mathrm{CO} ; 2$.

McPherson, R. A., and Coauthors, 2007: Statewide monitoring of the mesoscale environment: A technical update of the Oklahoma Mesonet. J. Atmos. Oceanic Technol., 24, 301-321, doi:10.1175/JTECH1976.1.

Parsons, D. A., 1941: Calibration of a Weather Bureau tippingbucket raingage. Mon. Wea. Rev., 69, 205, doi:10.1175/ 1520-0493(1941)069<0205:COAWBT>2.0.CO;2.

Petersen, D. A., and W. H. Beasley, 2013: High-speed video observations of a natural negative stepped leader and subsequent dart-stepped leader. J. Geophys. Res., 118, 12110-12119, doi:10.1002/2013JD019910.

Sieck, L. C., S. J. Burges, and M. Steiner, 2007: Challenges in obtaining reliable measurements of point rainfall. Water Resour. Res., 43, W01420, doi:10.1029/2005WR004519.

WMO, 2008: Precipitation gauge errors and corrections. Guide to Meteorological Instruments and Methods of Observation, 7th ed. WMO-8, I.6-6-I.6-7. 